\title{
A Unique Genetic and Biochemical Presentation of Fish-Eye Disease
}

\author{
Jan Albert Kuivenhoven, Eveline J. G. M. van Voorst tot Voorst, ${ }^{*}$ Heiko Wiebusch, ${ }^{\ddagger}$ Santica M. Marcovina, $\$$ \\ Harald Funke, ${ }^{*}$ Gerd Assmann, ${ }^{\ddagger}$ P. Haydn Pritchard," and John J. P. Kastelein \\ With the technical assistance of John Hill, Lida Adler, and Abdellatif Errrami \\ Department of Haemostasis, Thrombosis, Atherosclerosis and Inflammation Research, Academic Medical Centre, University of \\ Amsterdam, 1105 AZ Amsterdam, The Netherlands; *Department of Clinical Chemistry, Hospital De Weezenlanden, 8000 GM Zwolle, \\ The Netherlands; ${ }^{\ddagger}$ Institut für Arterioskleroseforschung, Westphälische Wilhelms-Universität Münster, D-4400 Münster, Germany; \\ ${ }^{\S}$ Northwest Lipid Research Laboratories, University of Washington, Seattle, Washington 98103; and "Atherosclerosis Specialty \\ Laboratory, Department of Pathology and Laboratory Medicine, St. Paul's Hospital and University of British Columbia, \\ Vancouver, British Columbia, Canada, V5Z 4H4
}

\section{Abstract}

This paper describes a novel genetic defect which causes fish-eye disease in four homozygous probands and its biochemical presentation in 34 heterozygous siblings. The male index patient presented with premature coronary artery disease, corneal opacification, HDL deficiency, and a near total loss of plasma lecithin:cholesterol acyltransferase (LCAT) activity. Sequencing of the $L C A T$ gene revealed homozygosity for a novel missense mutation resulting in an Asp ${ }^{131}$. Asn (N131D) substitution. Heterozygotes showed a highly significant reduction of HDL-cholesterol and apolipoprotein A-I levels as compared with controls which was associated with a specific decrease of LpA-I:A-II particles. Functional assessment of this mutation revealed loss of specific activity of recombinant $\mathrm{LCAT}_{\mathrm{N} 131 \mathrm{D}}$ against proteoliposomes. Unlike other mutations causing fish-eye disease, recombinant LCAT $_{\text {N131D }}$ also showed a $75 \%$ reduction in specific activity against LDL. These unique biochemical characteristics reveal the heterogeneity of phenotypic expression of $L C A T$ gene defects within a range specified by complete loss of LCAT activity and the specific loss of activity against HDL. The impact of this mutation on HDL levels and HDL subclass distribution may be related to the premature coronary artery disease observed in the male probands. (J. Clin. Invest. 1995. 96:2783-2791.) Key words: HDL deficiency •

Portions of this work were presented in abstract form at the 10th International Symposium on Atherosclerosis in Montréal on 9-14 October 1994.

Address correspondence to J. A. Kuivenhoven, Academic Medical Centre, Department of Vascular Medicine (G1-114), Meibergdreef 9, 1105 AZ Amsterdam, The Netherlands. Phone: 20-5665989; FAX: 206968833.

Received for publication 30 March 1995 and accepted in revised form 31 July 1995.

1. Abbreviations used in this paper: BHK, baby hamster kidney; CAD coronary artery disease; CER, cholesterol esterification rate; FC, free cholesterol; FED, fish-eye disease; FER, fractional esterification rate; LCAT, lecithin:cholesterol acyltransferase; LpA-I, lipoproteins containing apo A-I only; LpA-I:A-II, lipoproteins containing apo A-I and apo A-II; r, recombinant; TC, total cholesterol; TG, triglycerides.

J. Clin. Invest.

(C) The American Society for Clinical Investigation, Inc.

0021-9738/95/12/2783/09\$2.00

Volume 96, December 1995, 2783-2791 corneal opacities • coronary artery disease • lecithin:cholesterol acyltransferase

\section{Introduction}

Lecithin:cholesterol acyltransferase (LCAT) ${ }^{1}$ is a glycoprotein with an apparent molecular mass of $67 \mathrm{kD}$ which catalyzes the transfer of $s n-2$ fatty acids from phosphatidylcholine to the 3hydroxyl group of cholesterol, producing lysophosphatidylcholine and cholesteryl ester (1). LCAT is secreted by the liver and circulates in blood where it is bound to lipoproteins. This enzyme is responsible for cholesterol ester formation and, hence, plays a central role in HDL metabolism. apo A-I, the major structural protein of HDL particles, is regarded to be the principle activator of LCAT. Most of the cholesterol esterification takes place in the HDL fraction $(2,3)$ although LCAT may also act directly on lipoproteins of lower density (5). Generated cholesteryl esters are packed into the hydrophobic core of lipoproteins and, via the action of cholesteryl ester transfer protein, subsequently directed towards the liver. This model of reverse cholesterol transport, proposed by Glomset et al. $(6,7)$, is widely accepted. The esterification of cholesterol in HDL may maintain a free cholesterol gradient between peripheral tissue (and/or donor lipoproteins) and acceptor particles; therefore LCAT is thought to play a central role in reverse cholesterol transport.

The human LCAT gene has been cloned and the genomic DNA encompasses $4.2 \mathrm{~kb}$ and is composed of six exons and five introns. LCAT expression is confined mainly to the liver (8). The mature protein consists of 416 amino acids with a hydrophobic leader of 24 residues (9) and contains four $N$ glycosylation sites (10).

Until now, mutations in the $L C A T$ gene have been reported to underlie either classical LCAT deficiency or fish-eye disease (FED). Both disorders are inherited in an autosomal recessive manner and are characterized by severe HDL deficiency in homozygotes (11). LCAT deficiency is associated with a total loss of LCAT activity and a marked increase in the ratio of cholesterol to cholesteryl ester in plasma of homozygotes. Clinical symptoms include corneal opacities, hemolytic anemia, and frequently, though not invariably, proteinuria. Renal failure is sometimes a life-threatening complication in these patients (11). By contrast, LCAT function is only partially impaired in FED, in that the enzyme is not able to esterify cholesterol in HDL particles, whereas it retains its activity in the presence of cholesterol on VLDL and LDL $(12,13)$. The latter action results in the generation of near normal levels of plasma cholesteryl esters. Pronounced corneal opacification, as the result of 


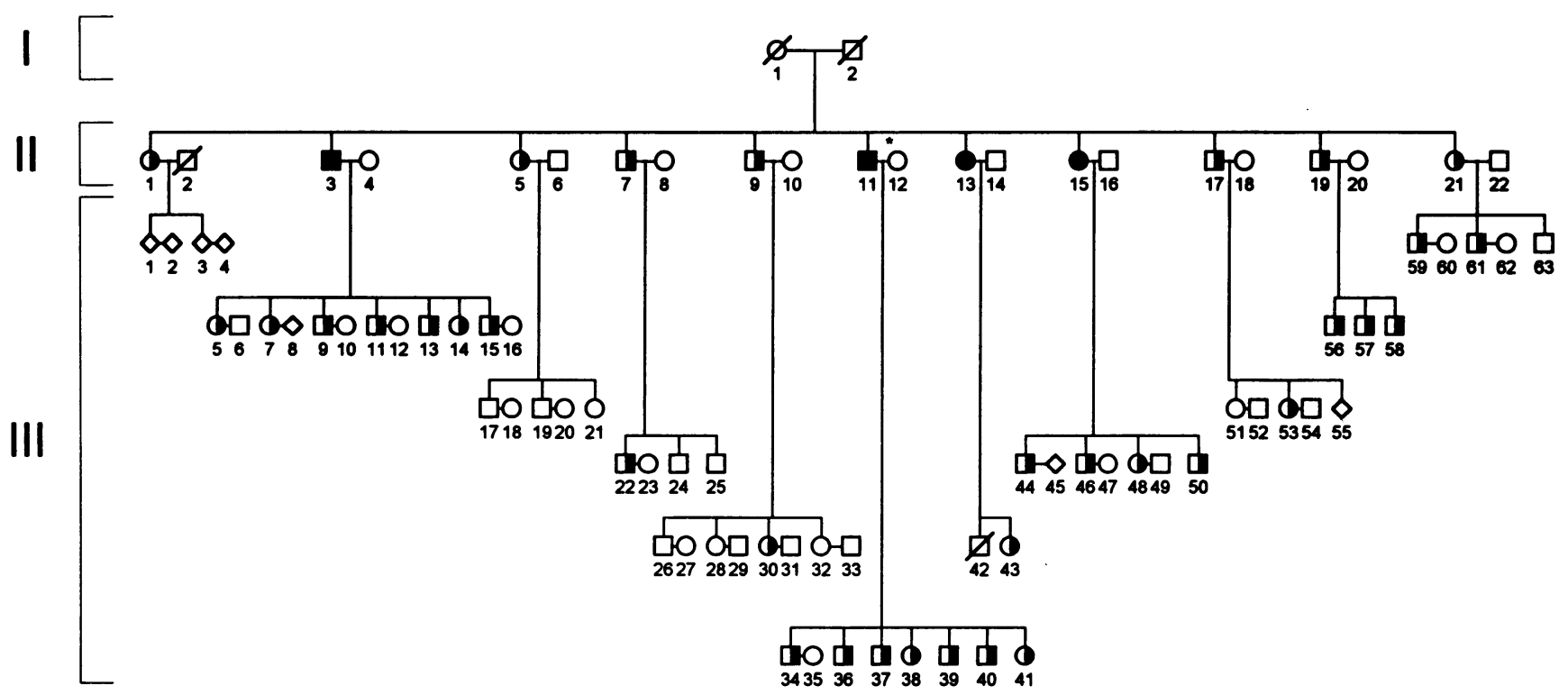

Figure 1. Pedigree of the kindred investigated. The index patient (II-11; denoted with an asterisk) proved to be homozygous for an $A^{2205}-\mathrm{G}$ nucleotide substitution in exon 4 of the LCAT gene (Fig. 2), resulting in the exchange of asparagine residue for an aspartic acid at position 131 (N131D). The DNA of the family members was screened for the presence of this mutation by using mutagenic PCR and restriction analysis. Squares and circles represent males and females, respectively, whereby fully shaded symbols indicate homozygotes and half shaded symbols indicate heterozygotes for the LCAT defect. Triangular symbols indicate subjects that were not available for investigation. Diagonal bars indicate deceased patients.

lipid depositions in the cornea, is the only evident clinical manifestation in FED. Although plasma HDL-cholesterol levels are $\sim 10 \%$ of normal in homozygotes, it is unclear whether LCAT deficiencies are associated with an increased risk of coronary artery disease $(C A D)(14,14 a)$.

Several mutations of the LCAT gene which are causative for FED or LCAT deficiency have now been described (12, 15-24). In vitro analysis of the encoded mutant proteins has proven the original hypothesis of Carlson and Holmquist (13, 25) which suggested that LCAT in FED had minimal activity against cholesterol in HDL yet retained activity against cholesterol in LDL (26).

In this report, we describe the elucidation and in vitro assessment of a novel missense mutation in the LCAT gene underlying HDL deficiency and pronounced corneal opacities in four homozygous probands of a very large family of Dutch descent. In vitro recreation and expression of this mutation identified a novel class of mutant LCAT whose biochemical characteristics were intermediate between the features of LCATs causing classical LCAT deficiency or FED. The large number of heterozygous siblings enabled us to study the impact of this mutation on lipoprotein metabolism.

\section{Methods}

Family history. Two brothers, 64 and 58 yr of age, and two sisters, 57 and $55 \mathrm{yr}$ of age, of a kindred with 11 siblings, presented with bilateral corneal opacities that almost entirely covered the irises, resulting in visual impairment. The parents died at ages 86 and 76. Until now, we were not able to determine consanguinity. The elder brother (II-3; Fig. 1) received coronary bypass surgeries at 54 and $64 \mathrm{yr}$ of age. The younger brother (II-11; Fig. 1) received a Bjork-Shiley aortic valve prosthesis for aortic valve stenosis and regurgitation at the age of 41 . 2 yr later coronary atherosclerosis was diagnosed by coronary angiogra- phy performed preoperatively. The two sisters who also presented with corneal opacities are alive and well.

Blood samples and DNA isolation. Blood was collected in EDTA tubes after an overnight fast and placed immediately on wet ice. Plasma was separated from cells by centrifugation $\left(1,2000 \mathrm{~g} ; 15 \mathrm{~min} ; 4^{\circ} \mathrm{C}\right)$, frozen in liquid nitrogen, and stored at $-70^{\circ} \mathrm{C}$ before shipment to Vancouver where various LCAT activity measurements were performed. Genomic DNA was extracted from white cells as described previously $(27,28)$.

Lipoprotein and apolipoprotein analysis. Total cholesterol (TC) and triglycerides (TG) were determined by established enzymatic methods $(29,30)$. HDL-cholesterol was determined as cholesterol remaining after precipitation of apo B-containing lipoproteins by phosphotungstate- $\mathrm{MgCl}_{2}$ (31). LDL-cholesterol was calculated using the Friedewald formula (32). A direct LDL-cholesterol quantitation by immunoseparation (33) was used when TG exceeded $4.5 \mathrm{mmol} / \mathrm{liter}$. Plasma apo AI, apo B-100, and lipoprotein(a) were measured by rate nephelometric immunoassays $(34,35)$. Plasma and HDL-free cholesterol (FC) were determined using an enzymatic colorimetric method (Boehringer-Mannheim GmbH, Mannheim, Germany). Quantification of LpA-I particles in plasma was performed by electroimmunodiffusion in agarose gel using Hydragel LpA-I particles kits (Sebia, Issy-les-Moulineaux, France). LpA-I represents the amount of plasma apo A-I which is not present in the LpA-I:A-II particles, whereas LpA-I:A-II is calculated by subtraction of the LpA-I from the total amount of plasma apo A-I (36).

LCAT concentration, LCAT activities, and measurement of the cholesterol esterification rate (CER). LCAT concentration was quantitated by radioimmunoassay using a polyclonal antibody raised against human LCAT (37). LCAT activity was determined as described previously (38) and represents the ability of plasma to esterify cholesterol in an exogenously presented proteoliposome substrate, whereas CER reflects the esterification of cholesterol within endogenous lipoproteins of the plasma. CER was determined by measuring the rate of esterification of $\left[{ }^{3} \mathrm{H}\right]$ cholesterol as described previously (39). The fractional esterification rate (FER) was calculated as the difference between the percentage of radioactive cholesterol esterified before and after incubation (CE/ 


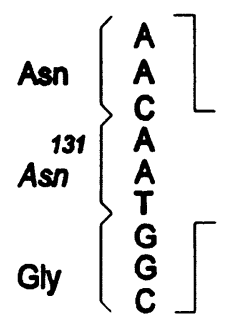

G $A$ T C

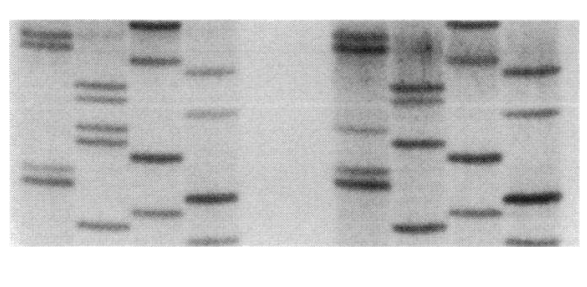

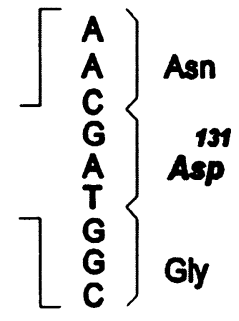

Figure 2. Autoradiogram showing the index patient to be homozygous for an $A^{2205}$ - $G$ nucleotide substitution in exon 4 of the LCAT gene, resulting in Asn ${ }^{131}$-Asp (N131D). Results were obtained by direct PCR solid-phase sequencing using ${ }^{35} \mathrm{~S}$-dATP.
$[\mathrm{FC}+\mathrm{CE}]) \times 100 \%)$. For each experimental series, an aliquot of frozen, normolipidemic plasma was used for quality control. CER was measured in both plasma and LDL/VLDL-depleted plasma. LDL/VLDL-depleted plasma was prepared by precipitation of apo $\mathrm{B}$-containing lipoproteins with phosphotungstate- $\mathrm{MgCl}_{2}(40,41)$. CERs were calculated from FERs and plasma- and HDL-FC levels, respectively, as described previously (42).

Amplification of LCAT fragments by PCR. Lower strand primers used in the PCR reactions were biotinylated at their 5 '-end using biotinphosphoramidite (Glen Research Corp., Sterling, VA). Sequencing primers were fluorescence-labeled at their 5 '-end using fluorescein amidite (FluorePrime; Pharmacia LKB Biotechnology, Piscataway, $\mathrm{NJ})$. Three DNA fragments, encompassing exon $1 / 2$, exon $3 / 4 / 5$, and exon 6 of the LCAT gene, respectively, were amplified by PCR from genomic DNA of the proband and a control subject using a DNA thermal cycler (Perkin Elmer Corp., Norwalk, CT). The amplification reactions were carried out in $10 \mathrm{mM}$ Tris- $\mathrm{HCl}(\mathrm{pH} 9.0), 50 \mathrm{mM} \mathrm{KCl}, 0.1 \%$ wt/ vol gelatin, $1.5 \mathrm{mM} \mathrm{MgCl} 2,1 \%$ Triton X-100, $0.2 \mathrm{mg} / \mathrm{ml}$ bovine serum albumin, containing $0.5-1.0 \mu \mathrm{g}$ genomic DNA, and final concentrations of $200 \mu \mathrm{M}$ dNTPs and $0.2-0.3 \mu \mathrm{M}$ primers in a total volume of $50 \mu \mathrm{l}$. After initial denaturation $\left(10 \mathrm{~min}, 95^{\circ} \mathrm{C}\right), 0.3-1.0 \mathrm{U}$ thermostable DNA polymerase (Supertaq; HT Biotechnology Ltd., Cambridge, United Kingdom) was added. Subsequently, 30 amplification cycles were performed: $95^{\circ} \mathrm{C}(1 \mathrm{~min}), 65^{\circ} \mathrm{C}(1 \mathrm{~min}), 72^{\circ} \mathrm{C}(1 \mathrm{~min})$, with a final extension step of $10 \mathrm{~min}$ at $72^{\circ} \mathrm{C}$. PCR products were analyzed on 2 $3 \%$ agarose gels.

Sequence analysis. PCR products were treated as described previously (12). For sequence analysis $\sim 3-4 \mu \mathrm{g}$ of DNA was incubated for $30 \mathrm{~min}$ at $37^{\circ} \mathrm{C}$ with $30 \mu \mathrm{l}$ streptavidin-coated Dynal-beads (Dynal A.S., Oslo, Norway) in a total volume of $100 \mu \mathrm{l}$ saline TE (STE: $1 \mathrm{M}$ $\mathrm{NaCl}, 5 \mathrm{mM}$ Tris (pH 7.4), $0.5 \mathrm{mM}$ Tris-EDTA). The supernatant was discarded, using a magnet particle concentrator (MPC-E; Dynal A.S.). After three washing steps with $100 \mu$ l STE, the beads were resuspended in $10 \mu \mathrm{l} 0.1 \mathrm{M} \mathrm{NaOH}$ and incubated for $10 \mathrm{~min}$ at room temperature. Single-stranded DNA in the supernatant was recovered and dissolved in demineralized water for subsequent sequencing. Beads were rinsed with $\mathrm{NaOH}$ followed by three subsequent washing steps with $10 \mathrm{mM}$ Tris ( $\mathrm{pH}$ 7.4), $1 \mathrm{mM}$ EDTA, and resuspended in $\mathrm{dH}_{2} \mathrm{O}$. Single-stranded DNA sequencing on both strands was performed to completion on an ALF sequencer using the AutoRead kit (both from Pharmacia LKB) and nested fluorescence-labeled sequencing primers.

Restriction analysis of PCR-amplified genomic DNA. A 135-bp portion of the LCAT gene, spanning the site of the missense mutation, was amplified by a mutagenic PCR from genomic DNA of the proband and his kindred (43). The lower strand primer was thus modified to create a SfaNI restriction site in the presence of the mutation: 5'-CGCGCACAGTCTCGTCCCGCACGTAGGCAT-3' (according to the sequence published by McLean et al. [8]), a method that has been used previously in LCAT genotyping $(12,19)$. The mismatch of one nucleotide is in bold and is underlined. PCR products were digested with SfaNI according to the instructions of the manufacturer (New England Biolabs, Beverly, MA), subjected to electrophoresis on a 3\% agarose gel, stained with ethidium bromide for visualization, and analyzed.
In vitro mutagenesis of LCAT cDNA and stable transfection of baby hamster kidney (BHK) cells. The missense mutation in codon 131 of exon $4\left(\mathrm{G}^{2205}-\mathrm{A}\right.$; N131D) was introduced into LCAT cDNA as described previously (26). The mutated LCAT cDNA construct was cloned into the mammalian pNUT expression vector $(44,45)$ using the unique restriction enzymes BsshII (Boehringer-Mannheim $\mathrm{GmbH}$ ) and Bpu1102I (New England Biolabs). The resulting pNUT-LCAT N131D construct was used to establish a stable cell line of BHK cells as described previously $(45,46)$. BHK cells were maintained in DMEM (Gibco-BRL, Mississauga, Ontario, Canada) supplemented with $10 \%$ heat-inactivated fetal bovine serum. Clones expressing recombinant ( $r$ ) LCAT $_{\mathrm{N} 131 \mathrm{D}}$ were identified by LCAT enzyme activity and solid-phase LCAT immunoassay as described by $O$ et al. (26). The specific activities of the wild-type and mutant rLCAT were determined using HDL analogues (egg yolk phosphatidylcholine:cholesterol liposomes preincubated with purified human apo A-I) and LDL as substrate as described previously (26).

Statistical analysis. To compare the biochemical characteristics of homozygotes (two male and two female) with unaffected sex- and agematched family members, we used the paired Student's $t$ test. To evaluate the influence of the genetic status and sex on various parameters and to explore possible interactions between these factors, ANOVA according to the General Linear Models procedure was used (47). In this analysis, heterozygotes were compared with unaffected individuals. These controls were either unaffected family members or subjects related by marriage or friendship.

\section{Results}

Genetic analysis and clinical features of the homozygotes. The index patient (II-11) presented with corneal opacities and severe HDL deficiency. Subsequent biochemical analysis revealed a loss of plasma LCAT activity despite a low normal CER (Table I) and a normal ratio of unesterified:esterified cholesterol ( Table II). This presentation was indicative of FED, and since it is known that mutations in the $L C A T$ gene are causative for this disorder $(12,15-18)$, we studied this gene as a candidate for the molecular basis of the clinical phenotype seen in this proband. Sequence analysis of the coding regions and consensus splice donor and acceptor sites of the LCAT gene of the index patient and a control was initially performed using an automatic sequencer. Direct PCR-based solid-phase automated sequencing showed that the proband was homozygous for a $A^{2205}-G$ substitution in exon 4 (according to the LCAT sequence reported by McLean et al. [8]), resulting in the exchange of an asparagine residue for an aspartic acid at position 131 of the mature protein. The autoradiogram in Fig. 2 shows the mutation, obtained by solid-phase single-stranded DNA sequencing using ${ }^{35}$ S-dATP. This base substitution was the only sequence change identified in the coding regions and consensus splice sites of the $L C A T$ 


\begin{tabular}{|c|c|c|c|c|c|c|c|c|c|}
\hline \multirow[b]{2}{*}{ Status* } & \multirow[b]{2}{*}{ Sex } & \multirow[b]{2}{*}{ Subject } & \multicolumn{4}{|c|}{ Plasma } & \multicolumn{3}{|c|}{ VLDL/LDL-depleted plasma } \\
\hline & & & LCAT activity & LCAT concentration & Specific activity & CER & LCAT activity & FER & CER \\
\hline & & & $n m o l / h \cdot m l$ & $\mu g / m l$ & $n m o l / h \cdot \mu g$ & $\mathrm{nmolh} \cdot \mathrm{ml}$ & $\mathrm{nmol} / \mathrm{h} \cdot \mathrm{ml}$ & $\%$ esterification/h & $n m o l h \cdot m l$ \\
\hline \multirow[t]{5}{*}{ Homozygote } & $\mathbf{M}$ & II-3 & 1.51 & 1.42 & 1.06 & 91 & 5.55 & 3.89 & 3.1 \\
\hline & $\mathbf{M}$ & II-11 & 1.46 & 1.74 & 0.84 & 55 & 5.37 & 5.05 & 4.0 \\
\hline & $\mathrm{F}$ & II-13 & 1.48 & 1.76 & 0.84 & 70 & 6.02 & 4.59 & 4.1 \\
\hline & $F$ & II-15 & 2.51 & 1.61 & 1.56 & 52 & 5.58 & 4.03 & 4.4 \\
\hline & & & $1.7 \pm 0.4$ & $1.6 \pm 0.1$ & $1.1 \pm 0.3$ & $67 \pm 15$ & $5.63 \pm 0.2$ & $4.39 \pm 0.46$ & $4 \pm 0.5$ \\
\hline \multirow[t]{2}{*}{ Heterozygote } & $\mathbf{M}$ & $(n=22)$ & $17.2 \pm 2.2^{\ddagger}$ & $3.6 \pm 0.7^{\ddagger}$ & $5.0 \pm 1.2$ & $84 \pm 29^{8}$ & $21.7 \pm 6.9^{\|}$ & $19.5 \pm 7.6^{\prime}$ & $42 \pm 17$ \\
\hline & $\mathrm{F}$ & $(n=12)$ & $18.0 \pm 2.9^{\ddagger}$ & $3.5 \pm 0.6^{\ddagger}$ & $5.2 \pm 0.8$ & $93 \pm 28^{8}$ & $17.3 \pm 4.7^{\|}$ & $14.3 \pm 3.9^{\natural}$ & $38 \pm 17$ \\
\hline \multirow[t]{2}{*}{ Normal } & $\mathbf{M}$ & $(n=16)$ & $27.0 \pm 4.0$ & $5.0 \pm 0.8$ & $5.4 \pm 1.0$ & $95 \pm 24$ & $26.1 \pm 5.7$ & $15.2 \pm 7.6$ & $43 \pm 23$ \\
\hline & $\mathrm{F}$ & $(n=22)$ & $25.5 \pm 2.9$ & $4.7 \pm 0.9$ & $5.5 \pm 1.0$ & $112 \pm 34$ & $21.9 \pm 3.5$ & $11.4 \pm 5.3$ & $37 \pm 14$ \\
\hline
\end{tabular}

* Status of family members was determined by DNA analysis. Values represent single data for homozygous subjects and mean \pm SD for the specified groups. LCAT activity and CER were determined in plasma and VLDL/LDL-depleted plasma. Proteoliposomes were used as substrate in the LCAT activities assay. CERs represent cholesterol esterification using endogenous lipoproteins. ANOVA was carried out using the General Linear Models procedure (heterozygotes versus controls): ${ }^{8} P<0.05 ;{ }^{\natural} P<0.027$; $"$ $P<0.001 ;{ }^{\ddagger} P<0.0001$.

gene in the proband. The DNA of the family members was screened for the presence of this mutation by using mutagenic PCR and restriction analysis (Fig. 3). Using this method, three additional homozygotes, two sisters (II-13 and II-15) and a brother (II-3) of the index patient, and 34 heterozygotes were identified (see Fig. 1). All family members who were homozygous for the mutation presented with dense corneal opacification. The two male homozygotes suffered from premature CAD, which was manifest at ages 43 and 54, respectively. There was no evidence of CAD in the two female homozygotes in this family. The four probands presented with normal kidney function.

In vitro analysis of mutated rLCAT. Stable expression of mutated LCAT CDNA, containing the $\mathrm{A}^{2205}-\mathrm{G}$ mutation, in BHK cells, enabled us to determine the functional effects of the exchange of an Asn $^{131}$ for Asp (N131D) in the LCAT protein. Upon $48 \mathrm{~h}$ of incubation, media were harvested and assayed for LCAT mass and activity against both proteoliposomes and LDL as substrates. rLCAT $_{\mathrm{N} 131 \mathrm{D}}$ was secreted at similar levels to wild-type LCAT, as determined by solid-phase immunoassay (results not shown). No LCAT protein was detected in BHK cells transfected with an empty pNUT expression vector. Using proteoliposomes, the specific activity of $\operatorname{rLCAT}_{\mathrm{N} 131 \mathrm{D}}$ was $4 \%$ of wild-type $(4.3 \pm 0.6 \%$; three independent experiments carried out in duplicate), whereas the mutant protein showed $25 \%$ specific activity of wild-type against LDL as substrate $(25.5 \pm 3.8 \%$ of wild-type).

Lipid, lipoprotein, and apolipoprotein analysis. The results of the laboratory analysis of lipids, lipoproteins, and apolipoproteins are presented in Tables II and III. Homozygotes were

Table II. Lipids, Lipoproteins, apo B, and LDL-Cholesterol/apo B Ratios

\begin{tabular}{|c|c|c|c|c|c|c|c|c|c|c|}
\hline Status & Sex & Subject & TC & TG & LDL-Cholesterol & FC & FC/EC & $\operatorname{Lp}(\mathbf{a})^{\ddagger}$ & apo B & LDL Cholesterol/apo B \\
\hline & & & mmol/iter & mmolniter & mmolliter & mmolniter & & $m g / d l$ & $m g / d l$ & \\
\hline \multirow[t]{5}{*}{ Homozygote } & $\mathbf{M}$ & II-3 & 6.2 & 10.1 & 1.5 & 2.9 & 0.90 & 3 & 156 & 0.37 \\
\hline & $\mathbf{M}$ & II-11 & 9.2 & 6.9 & 5.2 & 2.5 & 0.36 & 43 & 311 & 0.73 \\
\hline & $\mathrm{F}$ & II-13 & 7.9 & 6.1 & 3.0 & 2.3 & 0.42 & 34 & 246 & 0.47 \\
\hline & $\mathrm{F}$ & II-15 & 5.7 & 2.2 & 4.5 & 1.7 & 0.41 & 2 & 165 & 1.06 \\
\hline & & & $7.3 \pm 1.4$ & $6.3 \pm 2.8^{\| \prime}$ & $3.6 \pm 1.4$ & $2.4 \pm 0.5^{9}$ & $0.52 \pm 0.2$ & 18 & $220 \pm 63^{\prime \prime}$ & $0.66 \pm 0.27 * *$ \\
\hline \multirow[t]{2}{*}{ Heterozygote } & $\mathbf{M}$ & $(n=22)$ & $5.1 \pm 1.0^{\ddagger \ddagger}$ & $1.6 \pm 0.8$ & $3.6 \pm 0.8$ & $1.4 \pm 0.3$ & $0.39 \pm 0.1$ & 11.4 & $116 \pm 29$ & $1.20 \pm 0.16^{\S \S}$ \\
\hline & $\mathbf{F}$ & $(n=12)$ & $5.2 \pm 1.2^{\ddagger \ddagger}$ & $1.4 \pm 0.5$ & $3.5 \pm 1.1$ & $1.5 \pm 0.3$ & $0.41 \pm 0.1$ & 10.1 & $114 \pm 33$ & $1.19 \pm 0.10^{\S 8}$ \\
\hline \multirow[t]{2}{*}{ Normal } & $\mathbf{M}$ & $(n=15)$ & $6.0 \pm 1.2$ & $1.5 \pm 1.8$ & $4.0 \pm 1.2$ & $1.5 \pm 0.2$ & $0.33 \pm 0.05$ & 15.0 & $117 \pm 37$ & $1.36 \pm 0.07$ \\
\hline & $\mathrm{F}$ & $(n=22)$ & $5.6 \pm 1.1$ & $1.1 \pm 0.4$ & $3.5 \pm 1.2$ & $1.6 \pm 0.3$ & $0.39 \pm 0.06$ & 12.6 & $106 \pm 32$ & $1.29 \pm 0.15$ \\
\hline
\end{tabular}

* Status of family members was determined by DNA analysis. Values represent single data for homozygous subjects and mean \pm SD for the specified groups. ${ }^{\ddagger} \mathrm{Lp}$ (a) data represent single values for homozygotes and median values for the specified groups. ${ }^{8} \mathrm{LDL}-\mathrm{cholesterol/apo} \mathrm{B} \mathrm{ratios} \mathrm{were}$ calculated after converting LDL-cholesterol values from mmol/liter to $\mathrm{mg} / \mathrm{dl}$. Data of homozygotes were compared with unaffected sex- and agematched family members using the Student's $t$ test: " $P<0.02 ; 1 P<0.044 ; * * P<0.005$. ANOVA was carried out using the General Linear Models procedure (heterozygotes versus controls): ${ }^{\ddagger \ddagger} P<0.02,{ }^{\S} P<0.0002$. 


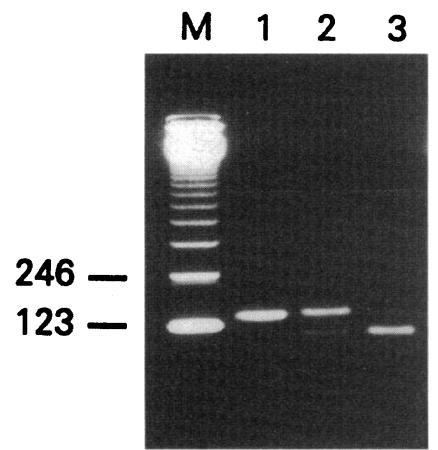

Figure 3. Screening method for the presence of the LCAT gene defect in the DNA of family members. A DNA fragment spanning the site of the $A^{2205}-G$ point mutation was amplified by PCR, whereby the upstream primer was thus modified, to create a SfaNI restriction site in the presence of the mutation. Lane $M$, molecular size standard; lane 1 , undigested PCR product of $135 \mathrm{bp}$; lane 2 shows partial cleavage of the PCR product indicative for heterozygosity, whereas lane 3 shows the digested PCR product of a homozygote.

compared with age- and sex-matched family members to test for potential significant differences. All four probands, i.e., II3, II-11, II-13, and II-15, presented with normal LDL-cholesterol and elevated apo B levels $(P<0.02)$, resulting in significantly decreased LDL-cholesterol/apo B ratios $(P<0.005)$. TC levels were elevated in subjects II-11 and II-13. Furthermore, TG were moderately elevated in II-3, II-11, and II-13, while subject II-15 presented with high normal TG levels. The increase of TG in homozygotes reached statistical significance $(P<0.02)$. Plasma FC levels were increased in all probands $(P<0.044)$, except for subject II-15. Severely reduced plasma HDL-cholesterol (10-15\% of normal; Table III) in the homozygotes was associated with a near total specific loss of LpA-I:A-II particles (Table III). LpA-I levels were low normal, whereas apo A-I levels were decreased to $\sim 30 \%$ of normal. Percentages of LpA-I exceeding $100 \%$ indicate differences in methods used to determine apo A-I levels (nephelometry and immunoelectrodiffusion).

34 heterozygotes identified by genetic analysis were compared with 38 controls. These controls were either family members or subjects related by marriage or friendship (see Fig. 1). Heterozygotes presented with decreased TC levels $(P<0.02$; Table II) and a significant reduction of LDL cholesterol/apo B ratios $(P<0.0002)$. Furthermore, TG and $L p(a)$ levels ap- peared unaffected by the genetic status. Comparison of the 22 male and 12 female heterozygotes indicated no significant differences. Table III shows a highly significant reduction of HDLcholesterol and apo A-I levels $(P<0.0001$; Table III) in both male and female heterozygotes. Despite this observation, neither plasma HDL cholesterol nor apo A-I levels could be used to predict the genotype for the 131 mutation in all individual cases (data not shown). The reduction of HDL-cholesterol in heterozygotes was associated with a slight though significant reduction of LpA-I levels $(P<0.047)$ and a highly significant reduction of LpA-I:A-II levels $(P<0.0001)$. This caused a significant increase in the percentage of apo A-I in LpA-I particles $(P<$ $0.025)$. Female heterozygotes showed a similar reduction of both LpA-I and LpA-I:A-II levels $(\sim 20 \%)$, whereas male heterozygotes showed a tendency towards a more specific reduction of LpA-I:A-II only (30 vs. 9\% reduction of LpA-I levels). Regarding all discussed parameters in this section, no significant interaction between gender and genetic status could be identified.

LCAT activities, LCAT concentration, and CERs. Homozygosity for the mutation presented in Fig. 2 cosegregated with a near total loss of plasma LCAT activity (5-9\% of normal) as measured with proteoliposomes as substrate in all four probands (Table I). The endogenous cholesterol esterification in whole plasma was either normal (II-3), low normal (II-13), or substantially reduced (II-11 and II-15, respectively). LCAT concentration and LCAT specific enzyme activity were also significantly reduced.

The decrease of LCAT activity in plasma was highly significant in both male and female heterozygotes as compared with unaffected subjects $(P<0.0001)$; however, it was not possible to determine the carrier status of some subjects on biochemical data only (data not shown). LCAT concentration was significantly reduced $(P<0.0001)$ as compared with controls, whereas the specific activity was largely unaffected. Cholesterol esterification in whole plasma was significantly reduced in heterozygotes $(P<0.05)$. The FER in LDL/VLDL-depleted plasma was significantly increased in both male and female heterozygotes $(P$ $<0.027$ ). No interaction between status and gender could be identified with respect to all LCAT parameters studied.

Table III. HDL-Cholesterol, apo A-I, and HDL Subfractions

\begin{tabular}{|c|c|c|c|c|c|c|c|}
\hline Status* & Sex & Subject & HDL-Cholesterol & apo A-I & LpA-I & LpA-I:A-II & \% LpA-I \\
\hline & & & mmolliter & $m g / d l$ & $m g / d l$ & $m g / d l$ & \\
\hline \multirow[t]{5}{*}{ Homozygote } & $\mathbf{M}$ & II-3 & 0.25 & 38 & 31 & 7 & 82 \\
\hline & $\mathbf{M}$ & II-11 & 0.14 & 25 & 32 & $<1$ & $>100$ \\
\hline & $\mathbf{F}$ & II-13 & 0.14 & 38 & 42 & $<1$ & $>100$ \\
\hline & $\mathrm{F}$ & II-15 & 0.18 & 40 & 44 & $<1$ & $>100$ \\
\hline & & $(n=4)$ & $0.18 \pm 0.04$ & $35 \pm 6$ & $37 \pm 6$ & 2 & $>100$ \\
\hline \multirow[t]{2}{*}{ Heterozygote } & $\mathbf{M}$ & $(n=22)$ & $0.81 \pm 0.23^{\ddagger}$ & $99 \pm 18^{\ddagger}$ & $44 \pm 8^{8}$ & $55 \pm 16^{\ddagger}$ & $45 \pm 8^{\| \prime}$ \\
\hline & $\mathrm{F}$ & $(n=12)$ & $1.04 \pm 0.15^{\ddagger}$ & $119 \pm 13^{\ddagger}$ & $49 \pm 7^{8}$ & $69 \pm 11^{\ddagger}$ & $42 \pm 4^{\| \prime}$ \\
\hline \multirow[t]{2}{*}{ Normal } & $\mathbf{M}$ & $(n=16)$ & $1.29 \pm 0.44$ & $125 \pm 25$ & $48 \pm 12$ & $78 \pm 19$ & $38 \pm 8$ \\
\hline & $\mathrm{F}$ & $(n=22)$ & $1.54 \pm 0.40$ & $147 \pm 24$ & $59 \pm 19$ & $88 \pm 18$ & $40 \pm 10$ \\
\hline
\end{tabular}

\footnotetext{
* Status of family members was determined by DNA analysis. Values represent single data for homozygous subjects and mean \pm SD for the specified groups. HDL subfraction determinations were carried out using immunoelectrodiffusion. ANOVA was carried out using the General Linear Models procedure (heterozygotes versus controls): ${ }^{8} P<0.047 ; " ~ P P<0.025 ;{ }^{\ddagger} P<0.0001$.
} 
$C A D$ and associated risk factors. The two male probands (II-3 and II-11) suffered from premature CAD at ages 54 and 43. Associated risk factors in these homozygotes include male sex and elevated total cholesterol in subject II-11 (Table II).

Body mass index, smoking and drinking habits, and physical activity were similar between normal and individuals (data not shown). The average ages of normal and affected males were 36 and $32 \mathrm{yr}$, respectively, whereas the average age of normal and affected females was $35 \mathrm{yr}$. There was no evidence for CAD in heterozygous siblings at the time the study was conducted. None of the subjects was on medication known to affect HDL cholesterol levels; however, subject II-3 used $10 \mathrm{mg}$ Zocor/d at the time his blood was drawn.

\section{Discussion}

A new mutation which underlies a unique FED phenotype. We identified homozygosity for an $\mathrm{A}^{2205}$ - $\mathrm{G}$ nucleotide substitution in exon 4 of the LCAT gene, resulting in an $A^{131}{ }^{131}$-Asp (N131D) substitution in the mature protein, in four FED probands of a large family of Dutch descent. Two female and two male homozygotes presented with HDL-cholesterol levels of $10-15 \%$ of normal in absence of proteinuria and abnormal renal function. They suffered from pronounced corneal opacities as singular clinical hallmark. Yet, the two male probands also presented with premature atherosclerosis. Associated risk factors in these homozygotes include male sex and elevated total cholesterol in subject II-11. Biochemical analysis showed that endogenous LCAT had lost its activity against proteoliposomes, whereas endogenous plasma cholesterol esterification was either normal or moderately reduced. According to this presentation, this familial disorder can be classified as FED. However, premature atherosclerosis is variably reported with this genetic disorder of HDL metabolism $(12,14,14 a, 16,48-50)$.

The novel mutation causing $\mathrm{LCAT}_{\mathrm{N} 131 \mathrm{D}}$ was the only mutation present in the LCAT exons and intron/exon boundaries. Furthermore, we failed to identify this mutation in the normal population or, indeed, other patients with FED. This together with the cosegregation of homozygosity for the defect with a near absolute loss of LCAT activity against proteoliposomes, as substrate lead us to suggest that this mutation is causative for this disorder.

The biochemical presentation of the four homozygotes in this kindred illustrates the features of this disorder: impaired endogenous LCAT activity as measured with proteoliposomes, low LCAT mass, low normal plasma cholesterol esterification, and high plasma FC. The clinical picture includes the presence of premature CAD in the two male probands suggesting to us that the earlier notion that no risk of CAD occurs in FED needs to be reevaluated (14a). By contrast, the absence of evidence of CAD in the female probands is consistent with the observation that premature CAD has not yet been described in any female with homozygous FED. The CAD in the male probands may be related to the significant increase in both TG and apo B levels. Moderate hypertriglyceridemia is observed in virtually all probands with FED $(12,17)$ and unpublished observations from our laboratories confirm the presence of high apo B levels in other families which harbor LCAT gene defects. Thus, we do not believe that the high apo B and TG seen in this family is due to another unrelated disorder. This notion is supported by the observation that the high apo B and TG does not present as a dominant trait in this family as would be expected for familial combined hyperlipidemia. Specifically, only $21 \%$ of the first degree family members have either high TG or apo B.

The decrease of LDL-cholesterol/apo B ratios in all four probands $(P<0.005$; versus unaffected sex- and age-matched family members) indicates that LDL particle composition is abnormal. This has not been observed previously in families with either classical LCAT deficiency or FED. However, FED probands have been shown to be characterized by an enrichment of LDL with TG $(50,51)$. Furthermore, Turner et al. (52) reported an impairment of lipoprotein processing, underlying the conversion of VLDL via IDL to LDL, in homozygotes for FED. The presence of small dense LDL particles in FED homozygotes could be a risk factor for atherosclerosis.

HDL-cholesterol deficiency in homozygotes was reflected by a specific loss of LpA-I:A-II particles as observed previously (53). Thus, the residual HDL-cholesterol (10-15\% of normal) consisted mainly of LpA-I particles. This is probably related to the selective effect of FED-related mutations on LpA-I:A-II metabolism as reported earlier (53). Since LpA-I is potentially more antiatherogenic than LpA-I:A-II (54-57), Rader et al. (53) have proposed that near normal LpA-I levels in FED probands might be related to their apparent relative low risk for atherosclerosis.

Heterozygosity for $L C A T_{N I 3 I D}$ is clinically significant. A unique feature of this study is the size of the family and the prevalence of the N131D defect among the siblings. The absence of unaffected siblings in the second generation suggests possible homozygosity of one of their parents but we were not able to confirm this. 4 probands, 34 heterozygotes, and 38 controls enabled us to analyze the effects of the $L C A T$ gene defect on lipoprotein metabolism in a similar genetic and environmental background.

The comparison of heterozygotes with unaffected family members with respect to lipids, lipoproteins, and apolipoproteins, revealed three interesting aspects. First, plasma total cholesterol levels were significantly decreased $(P<0.02)$. Second, affected siblings showed a significant decrease in LDL-cholesterol/apo B ratios $(P<0.0002)$ reflecting a changed LDL particle composition as already mentioned for homozygotes. However, the segregation of a low LDL/apo B ratio with the mutation was not unequivocal. We could not identify statistical differences in LDL/apo B ratios when comparing heterozygotes with the 10 unaffected first degree members of the kindred. However, male heterozygotes had significantly lower ratios $(P$ $<0.02$ ) when compared with the five unaffected male family members (data not shown). Third, the impact of the N131D defect on plasma HDL-cholesterol and apo A-I levels was striking in both sexes $(P<0.0001)$. On average, HDL-cholesterol levels were reduced by $0.5 \mathrm{mmol} /$ liter, mainly associated with a decrease in LpA-I:A-II levels $(P<0.0001)$, whereas LpA-I levels were only slightly affected $(P<0.02)$. Interestingly, male heterozygotes showed an $8 \%$ decrease in LpA-I levels whereas LpA-I:A-II levels were reduced by $30 \%$. By contrast, female heterozygotes presented with a $20 \%$ reduction of both LpA-I and LpA-I:A-II levels. These data might indicate differences in LpA-I and LpA-I:A-II metabolism between both sexes in the presence of mutated LCAT. Furthermore, decreased HDL-cholesterol in male heterozygotes seems to be mainly the result of altered LpA-I:A-II metabolism, whereas LpA-I levels normally account for the variation in $\operatorname{HDL}$-cholesterol $(58,59)$. Whether men would be at lower risk for atherosclerosis as the result of near normal levels of the antiatherogenic LpA-I frac- 
tion as compared with affected women cannot be concluded from this study. Further follow-up studies will possibly give an idea of the risk of atherosclerosis within this family.

Differences in LCAT function in heterozygotes of both sexes were clearly shown by the marked decrease of plasma LCAT activity $(P<0.0001)$. While determination of plasma LCAT activity using a proteoliposome substrate has been used previously to predict genotypes (48), we observed several instances in which the genetic status did not match the biochemical phenotype in this family. Thus, the use of a PCR-based test proved to be necessary to determine which subjects were affected. This observation may be related to the novel biochemical properties of this mutation of the LCAT gene.

Altered LCAT function in heterozygotes was confirmed by measuring the LCAT activity in VLDL/LDL-depleted plasma, although the decrease of LCAT activity in this plasma fraction varied greatly among the affected subjects, as reflected by the increased standard deviations as compared with LCAT activities measured in whole plasma. These results illustrate the need for genetic analysis in determining the carrier status of the family members.

Of interest, both male and female heterozygotes exhibited a significant increase of the FER in VLDL/LDL-depleted plasma (FER-HDL; $P<0.027)$. Dobiasova et al. $(60,61)$ showed an increase of FER-HDL in individuals that are at increased risk for CAD. FER-HDL was shown to reflect the metabolic activity and relative particle size distribution of the total HDL pool and was proposed to be a potential predictor of the risk of atherosclerosis $(60,61)$. These data constitute the first report of a monogenic cause of hypoalphalipoproteinemia and increased FER-HDL. Furthermore, our observations suggest a possible increased risk of atherosclerosis for subjects heterozygous for the N131D defect. They have a lipoprotein profile that others (on a different background) have proposed as a potential risk indicator $(62)$.

$L C A T_{N 131 D}$ is a novel class of mutant LCAT. To further characterize the effects of the mutation on LCAT function, the $\mathrm{A}^{2205}$-G nucleotide substitution was introduced into wild-type LCAT cDNA and cloned into a mammalian expression vector (pNUT). This construct was used for stable transfection of BHK cells. Since expression of the mutant LCAT occurred at near normal levels, we were able to assess the properties of the mutant enzyme. rLCAT $_{\mathrm{N} 131 \mathrm{D}}$ showed a near total loss of activity against proteoliposomes as substrate and only a residual $25 \%$ of normal activity against LDL as substrate. By contrast, the in vitro analysis of three other typical FED-related mutations, i.e., LCAT Thr123-Ile $_{\text {(26), LCAT Pro10-Leu }}$ (Pritchard, P. H., personal communication), and LCAT $_{\text {Prol0-Gln }}$ (reference 14a), showed only a specific loss of LCAT activity against HDL, whereas activity against LDL was mainly unaffected. By contrast, Klein et al. (17) reported a LCAT mutation (Del300) that did not result in loss of HDL-associated activity as shown by the functional assessment of this defect. They showed that the specific loss of LCAT activity against HDL only is not a prerequisite for a FED phenotype. In addition, our data indicate that partial LCAT activity against LDL in absence of activity against HDL can also underlie a FED phenotype. The in vitro analysis of the effects of mutations spread over the $L C A T$ gene exhibits a wide range of abnormal LCAT activity, varying from a complete loss of all LCAT activity (classical LCAT deficiency) to a specific loss of activity against HDL only (FED). Thus, these two disor- ders represent extremes of phenotypical expression of mutations of the LCAT gene.

Although homozygosity for the N131D defect results in an intermediate biochemical phenotype, the clinical manifestation is clearly compatible with FED characteristics. Partial LCAT activity against LDL is all that is required to sustain near normal plasma cholesterol esterification. This feature apparently prevents the development of classical LCAT deficiency.

However, the underlying background of the heterogeneity of biochemical and clinical expression of $L C A T$ gene defects remains to be elucidated. The LCAT region specified by the amino acid positions $123-135$ seems to be of specific interest since $\mathrm{Thr}^{123}$-IIe results in a specific loss of LCAT activity against HDL, yet Asn ${ }^{131}$-Asp is associated with an additional partial loss of activity against LDL. By contrast, Arg ${ }^{135}$-Trp/ Gln $(14,14 a)$ is characterized by a total loss of LCAT activity. Whether these mutations affect LCAT's catalytic function or its capacity to bind to and/or be active on different lipoprotein particles remains to be investigated.

The phenotypical expression of the mutant $\mathrm{LCAT}_{\mathrm{N} 131 \mathrm{D}}$ might explain the observed significant decrease of LDL-cholesterol/ apo B ratios in the probands and the heterozygotes; however, other possible gene defects might also have modulating effects. The decreased LCAT activity against LDL is distinctly different from the reported ability of FED LCAT to use LDL cholesterol $(13,14 a, 26)$. Altered transport of CE might have consequences for LDL particle composition and the atherogenic potential of this lipoprotein fraction. In addition, in the virtual absence of HDL-cholesterol in homozygotes, reverse cholesterol transport will probably be mainly driven by the partially impaired activity towards LDL particles.

Conclusions. In conclusion, this novel case of partial LCAT deficiency clearly indicates the differential expression of $L C A T$ gene mutations. The exchange of Asn ${ }^{131}$-Asp in the LCAT protein due to an $A^{2205}$ - $G$ nucleotide substitution in exon 4 of the LCAT gene results in a combined loss of LCAT activity against HDL and LDL ( 5 and $25 \%$ of normal, respectively). Homozygosity underlies dense corneal clouding and severe HDL deficiency, and seems to set male homozygotes at increased risk for atherosclerosis. Heterozygotes presented with affected lipoprotein metabolism, which might predispose them to an increased risk for atherosclerosis, a marked reduction of plasma HDL-cholesterol, a tendency towards small dense LDL, and an increase of FER-HDL. To elucidate the heterogeneity in phenotypical expression of $L C A T$ gene mutations, the LCAT region specified by the amino acid positions 123-135 appears to be of specific interest. This report clearly shows the importance of normal LCAT function in humans and indicates that the investigation of rare genetic syndromes like FED can provide important insights into LCAT function in lipoprotein metabolism.

\section{Acknowledgments}

We are indebted to all members of the family investigated whose enthusiasm and helpfulness enabled us to perform this study. Furthermore, we wish to thank the medical staff and the technicians of the Department of Clinical Chemistry of Hospital De Weezenlanden for the preliminary investigations and their invaluable support in providing us with the numerous DNA and plasma samples. This work could be performed thanks to the hospitality and technical support of all the laboratory members in both Münster and Vancouver. We are particularly indebted 
to Dr. J. J. Frohlich for his comments and encouragement. We would also like to thank Mr. Prins for performing the statistical analyses.

This project was supported by grants from the Dutch Heart Foundation (nr. 89201), the Diabetic Research Study Group Zwolle, the Medical Research Council of Canada, the Deutsche Forschungsgemeinschaft (SU179/1-1), and National Institutes of Health grant HL-30086. Dr. J. J. P. Kastelein is a clinical investigator of the Dutch Heart Foundation.

\section{References}

1. Glomset, J. A., and J. L. Wright. 1964. Some properties of a cholesterol esterifying enzyme in human plasma. Biochim. Biophys. Acta. 89:266-276.

2. Glomset, J. A. 1968. The plasma lecithin:cholesterol acyltransferase reaction. J. Lipid Res. 9:155-167.

3. Fielding, C. J., and P. E. Fielding. 1971. Purification and substrate specificity of lecithin:cholesterol acyltransferase from human plasma. FEBS Lett. 15:355358.

4. Deleted in proof

5. Carlson, L. A., and L. Holmquist. 1985. Evidence for the presence in human plasma of lecithin:cholesterol acyltransferase activity (beta-LCAT) specifically esterifying free cholesterol of combined pre-beta- and beta-lipoproteins. Studies of fish eye disease patients and control subjects. Acta Med. Scand. 218:197-205.

6. Glomset, J. 1972. Plasma lecithin:cholesterol acyltransferase. In Blood Lipids and Lipoproteins. G. Nelson, editor. John Wiley \& Sons Inc., New York. 745-787.

7. Glomset, J., K. R. Norum, and E. Gjone. 1983. Familial lecithin-cholesterol acyltransferase deficiency. In Metabolic Basis of Inherited Disease. J. B. Stanbury, J. B. Wyngaarden, D. S. Frederickson, J. L. Goldstein, and M. S. Brown, editors. McGraw-Hill Inc., New York. 643-654.

8. McLean, J., K. Wion, D. Drayna, C. Fielding, and R. Lawn. 1986. Human lecithin-cholesterol acyltransferase gene: complete gene sequence and sites of expression. Nuc. Acids Res. 14:9397-9406.

9. McLean, J., C. Fielding, D. Drayna, H. Dieplinger, B. Baer, W. Kohr, W. Henzel, and R. Lawn. 1986. Cloning and expression of human lecithin:cholesterol acyltransferase cDNA. Proc. Natl. Acad. Sci. USA. 83:2335-2339.

10. Jonas, A. 1991. Lecithin-cholesterol acyltransferase in the metabolism of high-density lipoproteins. Biochim. Biophys. Acta. 1084:205-220.

11. Norum, K. R., E. Gjone, and J. A. Glomset. 1989. Familial lecithin:cholesterol acyltransferase deficiency, including fish eye disease. In The Metabolic Basis of Inherited Disease. C. R. Scriver, A. L. Beaudet, W. S. Sly, and D. Valle, editors. McGraw-Hill Inc., New York. 1181-1194.

12. Funke, H., A. von Eckardstein, P. H. Pritchard, J. J. Albers, J. J. P. Kastelein, C. Droste, and G. Assmann. 1991. A molecular defect causing fish eye disease: an amino acid exchange in lecithin-cholesterol acyltransferase (LCAT) leads to the selective loss of alpha-LCAT activity. Proc. Natl. Acad. Sci. USA. 88:4855-4859.

13. Carlson, L. A., and L. Holmquist. 1985. Evidence for deficiency of high density lipoprotein lecithin:cholesterol acyltransferase activity (alpha-LCAT) in fish eye disease. Acta Med. Scand. 218:189-196.

14. Assmann, G., A. von Eckardstein, and H. Funke. 1991. Lecithin:cholestero acyltransferase deficiency and fish-eye disease. Curr. Opin. Lipidol. 2:110-117.

14a. Kuivenhoven, J. A., A. F. H. Stalenhoef, J. S. Hill, P. N. M. Demacker, A. Errrami, J. J. P. Kastelein, and P. H. Pritchard. 1995. Two novel molecular defects in the LCAT gene are associated with fish-eye disease. Journal of Arteriosclerosis, Thrombosis and Vascular Biology. In press.

15. Skretting, G., and H. Prydz. 1992. An amino acid exchange in exon I of the human lecithin:cholesterol acyltransferase ( $L C A T)$ gene is associated with fish eye disease. Biochem. Biophys. Res. Commun. 182:583-587.

16. Klein, H. G., P. Lohse, P. H. Pritchard, D. Bojanovski, H. Schmidt, and H. B. Brewer, Jr. 1992. Two different allelic mutations in the lecithin-cholestero acyltransferase gene associated with the fish eye syndrome. Lecithin-cholestero acyltransferase ( $\mathrm{Thr}^{123}$-Ile) and lecithin-cholesterol acyltransferase ( $\mathrm{Thr}^{347}-\mathrm{Met}$ ) J. Clin. Invest. 89:499-506.

17. Klein, H. G., S. Santamarina-Fojo, N. Duverger, M. Clerc, M. F. Dumon, J. J. Albers, S. Marcovina, and H. B. Brewer, Jr. 1993. Fish eye syndrome: a molecular defect in the lecithin-cholesterol acyltransferase (LCAT) gene associated with normal $\alpha$-LCAT-specific activity. Implications for classification and prognosis. J. Clin. Invest. 92:479-485.

18. von Eckardstein, A., H. Funke, P. H. Pritchard, J. J. Albers, J. J. P Kastelein, C. Droste, and G. Assmann. 1990. Fish-eye disease: characterization of the molecular defect. Circulation. 82:425a. (Abstr.)

19. Funke, H., A. von Eckardstein, P. H. Pritchard, A. E. Hornby, H. Wiebusch, C. Motti, M. R. Hayden, C. Dachet, B. Jacotot, U. Gerdes, et al. 1993. Genetic and phenotypic heterogeneity in familial lecithin:cholesterol acyltransferase (LCAT) deficiency. Six newly identified defective alleles further contribute to the structural heterogeneity in this disease. J. Clin. Invest. 91:677-683.

20. Klein, H. G., P. Lohse, N. Duverger, J. J. Albers, D. J. Rader, L. A. Zech, S. Santamarina-Fojo, and H. B. Brewer, Jr. 1993. Two different allelic mutations in the lecithin:cholesterol acyltransferase ( $L C A T)$ gene resulting in classic LCAT deficiency: LCAT ( $\operatorname{tyr}^{83}$ to stop) and LCAT (tyr ${ }^{156}$ to asn ). J. Lipid Res. 34:4958.

21. Bujo. H., J. Kusunoki, M. Ogasawara, T. Yamamoto, Y. Ohta, T. Shimada, Y. Saito, and S. Yoshida. 1991. Molecular defect in familial lecithin:cholesterol acyltransferase (LCAT) deficiency: a single nucleotide insertion in LCAT gene causes a complete deficient type of the disease. Biochem. Biophys. Res. Commun. 181:933-940.

22. Taramelli, R., M. Pontoglio, G. Candiani, S. Ottolenghi, H. Dieplinger, A. Catapano, J. Albers, C. Vergani, and J. McLean. 1990. Lecithin cholesterol acyl transferase deficiency: molecular analysis of a mutated allele. Hum. Genet. 85:195-199.

23. Gotoda, T., N. Yamada, T. Murase, M. Sakuma, N. Murayama, H. Shimano, K. Kozaki, J. J. Albers, Y. Yazaki, and Y. Akanuma. 1991. Differential phenotypic expression by three mutant alleles in familial lecithin:cholesterol acyltransferase deficiency. Lancet. 338:778-781.

24. Maeda, E., Y. Naka, T. Matozaki, M. Sakuma, Y. Akanuma, G. Yoshino, and M. Kasuga. 1991. Lecithin-cholesterol acyltransferase (LCAT) deficiency with a missense mutation in exon 6 of the LCAT gene. Biochem. Biophys. Res. Commun. 178:460-466.

25. Holmquist, L., and L. A. Carlson. 1987. Alpha-lecithin:cholesterol acyltransferase deficiency. Lack of both phospholipase A2 and acyltransferase activities characteristic of high density lipoprotein lecithin:cholesterol acyltransferase in fish eye disease. Acta Med. Scand. 222:23-26.

26. O, K., J. S. Hill, X. Wang, and P. H. Pritchard. 1993. Recombinant lecithin:cholesterol acyltransferase containing a $\mathrm{Thr}^{123}$ to Ile mutation esterifies cholesterol in low density lipoprotein but not in high density lipoprotein. J. Lipid Res. 34:81-88.

27. Southern, E. M. 1975. Detection of specific sequences among DNA fragments separated by gel electrophoresis. J. Mol. Biol. 98:503-517.

28. Hayden, M. R., H. Kirk, C. Clark, J. Frohlich, S. Rabkin, R. MacLeod, and J. Hewitt. 1987. DNA polymorphisms in and around the APO-AI-CIII genes and genetic hyperlipidemia. Am. J. Hum. Genet. 40:421-430.

29. Siedel, J., E. O. Hagele, J. Ziegenhorn, and A. W. Wahlefeld. 1983. Reagent for the enzymatic determination of serum total cholesterol with improved lipolytic efficiency. Clin. Chem. 29:1075-1080.

30. Wahlefeld, A. W. 1974. Triglyceride determination after enzymatic hydrolysis. In Methods in Enzymatic Analysis. H. U. Bergmeyer, editor. Academic Press, New York. 1831-1835.

31. Lopes-Virella, M. F., P. Stone, S. Ellis, and J. A. Colwell. 1977. Cholesterol determination in high density lipoproteins separated by three different methods. Clin. Chem. 23:882-884.

32. Friedewald, W. T., R. I. Levy, and D. S. Fredrickson. 1972. Estimation of the concentration of low-density lipoprotein in plasma, without use of the preparative ultracentrifuge. Clin. Chem. 18:499-502.

33. Teng Leary, E., G. Tjerland, and G. R. Warnick. 1993. Evaluation of the enzyme immunoseparation reagent for direct quantitation of LDL cholesterol. Clin. Chem. 39:1124-1125a. (Abstr.)

34. Labeur, C., J. Shepherd, and M. Rosseneu. 1990. Immunological assays of apolipoproteins in plasma: methods and instrumentation. Clin. Chem. 36:591 597.

35. Gillery, P., P. Arthuis, C. Cuperlier, and R. Circaud. 1993. Rate nephelometry assay of serum lipoprotein(a). Clin. Chem. 39:503-507.

36. Parra, H. J., H. Mezdour, N. Ghalim, J. M. Bard, and J. C. Fruchart. 1990. Differential electroimmunoassay of human LpA-I lipoprotein particles on readyto-use plates. Clin. Chem. 36:1431-1435

37. Albers, J. J., J. C. Adolphson, and C. H. Chen. 1981. Radioimmunoassay of human lecithin-cholesterol acyltransferase. J. Clin. Invest. 67:141-148.

38. Frohlich, J., R. McLeod, P. H. Pritchard, J. Fesmire, and W. McConathy. 1988. Plasma lipoprotein abnormalities in heterozygotes for familial lecithin:cholesterol acyltransferase deficiency. Metab. Clin. Exp. 37:3-8.

39. Dobiasova, M., and M. Schutzova. 1986. Cold labelled substrate and estimation of cholesterol esterification rate in lecithin cholesterol acyltransferase radioassay. Physiol. Bohemoslov. 35:319-327.

40. Warnick, G. R., T. Nguyen, and A. A. Albers. 1985. Comparison of improved precipitation methods for quantification of high-density lipoprotein cholesterol. Clin. Chem. 31:217-222.

41. Burnstein, M., H. R. Scholnick, and R. Morfin. 1970. Rapid method for the isolation of lipoproteins from human serum by precipitation with polyanions. J. Lipid Res. 11:583-595.

42. Stokke, K. T., and K. R. Norum. 1971. Determination of LCAT in human blood plasma. Scand. J. Clin. Lab. Invest. 27:21-27.

43. Kumar, R., and L. L. Dunn. 1989. Designed diagnostic restriction fragment polymorphisms for the detection of point mutations in ras oncogenes. Oncogene Res. 4:235-241.

44. Palmiter, R. D., R. R. Behringer, C. J. Quaife, F. Maxwell, I. H. Maxwell, and R. L. Brinster. 1987. Cell lineage ablation in transgenic mice by cell-specific expression of a toxin gene. Cell. 50:435-443.

45. Funk, W. D., R. T. A. MacGillivray, A. B. Mason, S. A. Brown, and R. C. Woodworth. 1990. Expression of the amino-terminal half-molecule of hu- 
man serum transferrin in cultured cells and characterization of the recombinant protein. Biochemistry. 29:1654-1660.

46. Hill, J. S., K. O, X. Wang, S. Paranjape, D. Dimitrijevich, A. G. Lacko, and P. H. Pritchard. 1993. Expression and characterization of recombinant human lecithin:cholesterol acyltransferase. J. Lipid Res. 34:1245-1251.

47. Armitage, P., and G. Berry. 1987. Statistical methods in medical research. In General Linear Models. Blackwell Scientific Publications, Oxford. 386-399.

48. Kastelein, J. J. P., P. H. Pritchard, D. W. Erkelens, J. A. Kuivenhoven, J. J. Albers, and J. J. Frohlich. 1992. Familial high-density-lipoprotein deficiency causing corneal opacities (fish-eye disease) in a family of Dutch descent. $J$. Intern. Med. 231:413-419.

49. Clerc, M., M. F. Dumon, D. Sess, M. Freneix Clerc, M. Mackness, and C. Conri. 1991. A "Fish-eye disease" familial condition with massive corneal opacities and hypoalphalipoproteinaemia: clinical, biochemical and genetic features. Eur. J. Clin. Invest. 21:616-624.

50. Carlson, L. A., and B. Philipson. 1979. Fish-eye disease: a new familial condition with massive corneal opacities and dyslipoproteinemia. Lancet. 2:921923.

51. Carlson, L. A. 1982. Fish eye disease: a new familial condition with massive corneal opacities and dyslipoproteinemia. Eur. J. Clin. Invest. 12:41-53.

52. Turner, P. R., L. A. Carlson, C. Cortese, S. Rao, B. Marenah, N. E. Miller, and B. Lewis. 1984. Studies of lipoprotein metabolism in a patient with fish-eye disease. Eur. J. Clin. Invest. 14:273-277.

53. Rader, D. J., K. Ikewaki, N. Duverger, H. Schmidt, P. H. Pritchard, J. J. Frohlich, M. Clerc, M. F. Dumon, T. Fairwell, L. Zech, et al. 1994. Markedly accelerated catabolism of apolipoprotein A-II (ApoA-II) and high density lipoproteins containing ApoA-II in classic lecithin:cholesterol acyltransferase deficiency and fish-eye disease. J. Clin. Invest. 93:321-330.

54. Puchois, P., A. Kandoussi, P. Fievet, J. L. Fourrier, M. Bertrand, E. Koren, and J. C. Fruchart. 1987. Apolipoprotein A-I containing lipoproteins in coronary artery disease. Atherosclerosis. 68:35-40.

55. Rader, D. J., G. Castro, L. A. Zech, J. C. Fruchart, and H. B. Brewer, Jr. 1991. In vivo metabolism of apolipoprotein A-I on high density lipoprotein particles LpA-I and LpA-I,A-II. J. Lipid Res. 32:1849-1859.

56. Atmeh, R. F., J. Shepherd, and C. J. Packard. 1983. Subpopulations of apolipoprotein A-I in human high-density lipoproteins. Their metabolic properties and response to drug therapy. Biochim. Biophys. Acta. 751:175-188.

57. Stampfer, M. J., F. M. Sacks, S. Salvini, W. C. Willett, and C. H. Hennekens. 1991. A prospective study of cholesterol, apolipoproteins, and the risk of myocardial infarction. $N$. Engl. J. Med. 325:373-381.

58. Cheung, M. C., and J. J. Albers. 1984. Characterization of lipoprotein particles isolated by immunoaffinity chromatography. Particles containing A-I and A-II and particles containing A-I but no A-II. J. Biol. Chem. 259:1220112209.

59. Cheung, M. C., B. G. Brown, A. C. Wolf, and J. J. Albers. 1991. Altered particle size distribution of apolipoprotein A-I-containing lipoproteins in subjects with coronary artery disease. J. Lipid Res. 32:383-394.

60. Dobiasova, M., J. Stribrna, P. H. Pritchard, and J. J. Frohlich. 1992. Cholesterol esterification rate in plasma depleted of very low and low density lipoproteins is controlled by the proportion of $\mathrm{HDL}_{2}$ and $\mathrm{HDL}_{3}$ subclasses: study in hypertensive and normal middle-aged and septuagenarian men. J. Lipid Res. 33:1411-1418.

61. Dobiasova, M., J. Stribrna, D. Sparks, P. H. Pritchard, and J. J. Frohlich. 1991. Cholesterol esterification rates in very low density lipoprotein- and low density lipoprotein-depleted plasma. Arterioscler. Thromb. 11:64-70.

62. Austin, M. A., M. C. King, K. M. Vranizan, and R. M. Krauss. 1990 Atherogenic lipoprotein phenotype. A proposed genetic marker for coronary heart disease risk. Circulation. 82:495-506. 